\title{
Psychiatry In Portugal - a brief historical review of the first century
}

A. Palma Alho ${ }^{1}$, N. Santos ${ }^{1}$, M. Martins ${ }^{1}$, R. Gasparinho ${ }^{1}$, N. Fernandes ${ }^{1}$, L. Ferreira ${ }^{1}$, A. Marques ${ }^{1}$, E. Seco ${ }^{1}$.

${ }^{1}$ Hospital Distrital de Santarém, Psiquiatria e Saúde Mental, Santarém, Portugal.

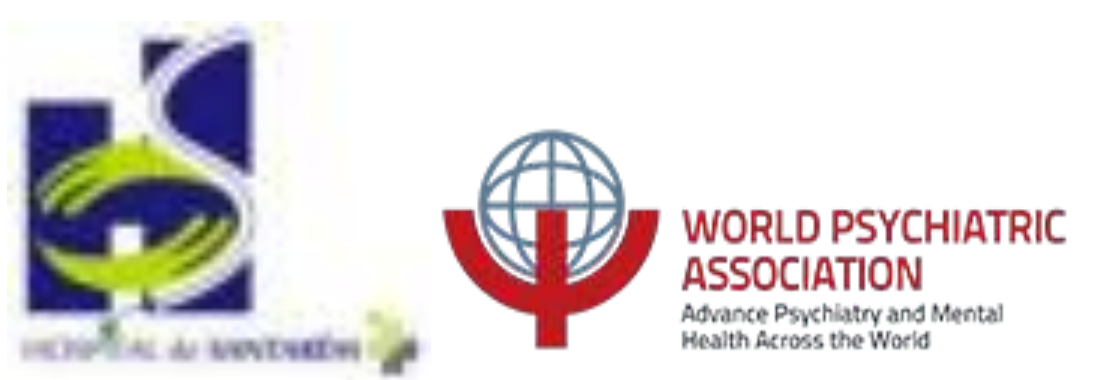

\section{OBJECTIVE}

To review the Portuguese Psychiatry History from its birth until 1945.

\section{BACKGROUND}

In the early $19^{\text {th }}$ century, in Portugal, mental health patients were held captive or kept in hospitals and left in poor sanitary conditions. The birth of Psychiatry as a medical field is thought to have occurred around 1835 , but it was only in 1848 that a new era began for Portuguese Psychiatry ${ }^{1}$.

\section{MATERIALS AND METHODS}

PubMed search with key terms "History", "Psychiatry" and "Portugal" (in English and Portuguese) together with consult of literature in paper regarding the same theme.

\section{RESULTS}

With the implementation of liberal ideals the Enlightenment principles eventually reached Portugal. A new attitude towards mental health and a more humanitarian purpose began, but having collective security in mind, its main goal was to hospitalize and isolate mental patients.

1848 Psychiatric patients started to receive an improved care, with the reconstruction of an ancient monastery to be the first psychiatric Hospital in Lisbon (Rilhafoles) ${ }^{1}$, thanks to Queen Mary the II and her prime-minister the Duke of Saldanha.

In 1910 this hospital was renamed Miguel Bombarda Hospital $(\mathrm{MBH})$, in memory of the doctor who was assasined by a patient in its premises ${ }^{2}$.

1883 Conde Ferreira Hospital was built in Oporto and was the first one to be specially designed for this purpose ${ }^{3}$. This hospital had defined procedures comparing to $\mathrm{MBH}$ and a complementary component devoted to histopathological studies of mental illness 1.
1893/1894 The Order of Hospitallers funded Casa de Saúde do Telhal for men and Casa de Saúde da Idanha for women, respectively.

1942 Opening of Júlio de Matos Hospital in Lisbon, a landmark of psychiatry in the post-world War $\mathrm{II}^{3}$. It was the first universitary hospital exclusively dedicated to Psychiatry and a place where the most recent biological treatments, advanced occupational therapies and psychotherapy methods started to be implemented ${ }^{4}$.

\section{5} Opening of Sobral Cid Hospital in Coimbra ${ }^{3}$.

It was also in this year that regional and general dispensaries were developed, to extend psychiatric care across the country ${ }^{4}$.

\section{CONCLUSIONS}

Despite the creation of well-structured Psychiatric facilities and a great mentality change towards mental illness in the first century, the scarcity of institutions and human resources and the need of more effective treatments remained a problem to be solved in the next half of the century.

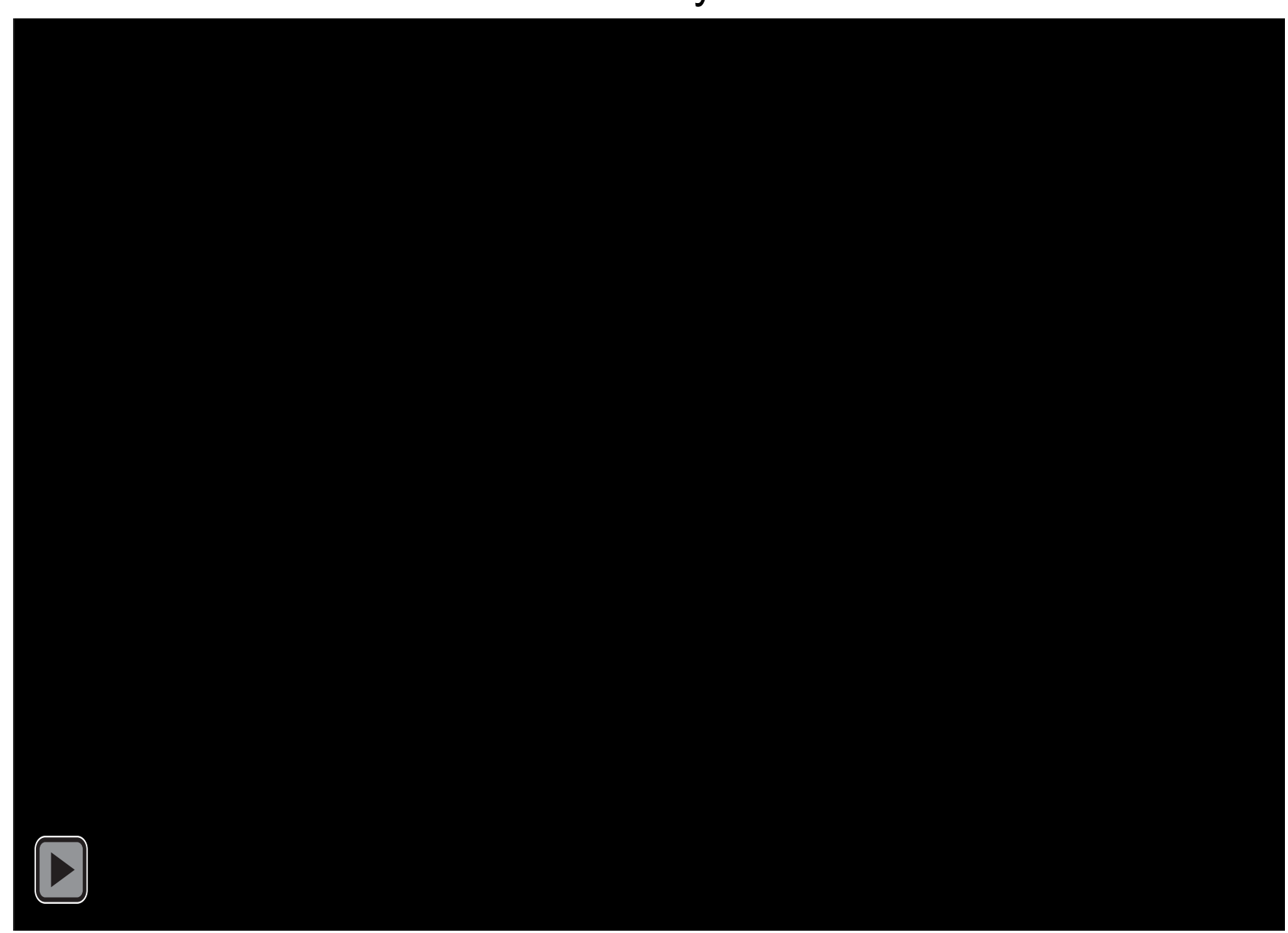

